\title{
Activation of platelet protease-activated receptor-1 induces epithelial-mesenchymal transition and chemotaxis of colon cancer cell line SW620
}

\author{
YITAO JIA ${ }^{1}$, SUQIAO ZHANG ${ }^{1}$, LINGLING MIAO $^{2,3}$, JINGBAO WANG $^{2}$, ZUJIAN JIN $^{2,4}$, BIN GU $^{2}$, \\ ZHIHUI DUAN ${ }^{2}$, ZHAOLONG ZHAO ${ }^{2}$, SHUNMAO MA ${ }^{5}$, WENJIN ZHANG ${ }^{6}$ and ZHONGXIN LI ${ }^{2}$ \\ ${ }^{1}$ Department of Oncology, Hebei General Hospital, Shijiazhuang, Hebei 050051; ${ }^{2}$ Second Department of Surgery, \\ The Fourth Hospital of Hebei Medical University, Shijiazhuang, Hebei 050011; ${ }^{3}$ Second Department of Surgery \\ The Bethune International Peace Hospital, Shijiazhuang, Hebei 050082; ${ }^{4}$ Department of Gynecology and Obstetrics, \\ The Yiwu Affiliated Hospital of Zhejiang University, Yiwu, Zhejiang 322000; ${ }^{5}$ Department of Surgery, \\ Hebei Medical University Affiliated North China Petroleum Bureau General Hospital, Renqiu, Hebei 062552; \\ ${ }^{6}$ Centre of Breast Cancer, The Fourth Hospital of Hebei Medical University, Shijiazhuang, Hebei 050011, P.R. China
}

Received December 3, 2014; Accepted March 6, 2015

DOI: $10.3892 / o r .2015 .3897$

\begin{abstract}
The aim of the present study was to examine the role of protease-activated receptor-1 (PAR1)-stimulated platelet activation in the epithelial-mesenchymal transition (EMT) and migration of colon cancer cells, and to identify the underlying mechanisms. TFLLR- $\mathrm{NH}_{2}$, a PAR1 agonist, was used to activate platelets and the platelet supernatants were used to treat the SW620 colon cancer cell line. Expression of E-cadherin and vimentin on SW620 cells was detected by immunofluorescence and western blotting, and the level of the transforming growth factor $\beta 1$ (TGF- $\beta 1$ ) was measured using ELISA following the activation of platelets by TFLLR-NH $\mathrm{N}_{2}$. miR-200b expression was detected using quantitative PCR in SW620 cells. In order to investigate the chemotactic ability of the SW620 cells, the expression of CXC chemokine receptor type 4 (CXCR4) was measured by flow cytometry. Transwell migration assays were performed following exposure of the cells to the supernatant of PAR1activated platelets. SW620 cells cultured in the supernatant of TFLLR-NH $\mathrm{H}_{2}$-activated platelets upregulated E-cadherin expression and downregulated the vimentin expression. In the in vitro platelet culture system, a TFLLR- $\mathrm{NH}_{2}$ dose-dependent increase of secreted TGF- $\beta 1$ was detected in the supernatant. The activation of PAR1 on the platelets led to the inhibition of miR-200b expression in the SW620 cells that were cultured
\end{abstract}

Correspondence to: Professor Zhongxin Li, Second Department of Surgery, The Fourth Hospital of Hebei Medical University, 169 Tianshan Road, Shijiazhuang, Hebei 050011, P.R. China E-mail: lizhongxin99@163.com

Key words: epithelial-mesenchymal transition, chemotaxis, platelet, protease activated receptor- 1 , transforming growth factor $\beta 1$, colorectal cancer in platelet-conditioned media. The number of SW620 cells that penetrated through the Transwell membrane increased with the dose of TFLLR-NH $\mathrm{H}_{2}$ used to treat the platelets. The percentage of CXCR4-positive SW620 cells was significantly higher when they were exposed to the supernatant of platelets cultured for $24 \mathrm{~h}$ with PAR1 agonist than when cultured in non-conditioned media $(40.89 \pm 6.74$ vs. $3.47 \pm 1.40 \%, \mathrm{P}<0.01)$. Platelet activation with a PAR1 agonist triggered TGF- $\beta$ secretion, which induced EMT of SW620 human colon cancer cells via the downregulation of $\mathrm{miR}-200 \mathrm{~b}$ expression, and activated platelets had a chemotactic effect on colon cancer cells mediated by the upregulation of CXCR4 on the cell surface.

\section{Introduction}

Regional or distal lymph-node metastasis is the major cause of mortality for patients with malignant tumors. Although tumor metastasis has been extensively studied, the exact mechanisms remain to be determined. Epithelial-mesenchymal transition (EMT) is a process whereby epithelial cells transform morphologically and phenotypically into fibroblasts or mesenchymal cells, and gain migratory ability (1). EMT is considered to be the first step of tumor metastasis (2,3). During EMT, epithelial cells lose their polarity and cell-cell adhesion, develop cytoskeletal changes and obtain increased migratory potential and mobility (4). This process is concurrent with the alteration of various molecular markers, including downregulation of the epithelial markers E-cadherin and $\beta$-catenin, and upregulation of the mesenchymal phenotypic markers vimentin and N-cadherin (5). EMT has been shown to be closely associated with the invasion and metastasis of various malignancies, including gastric, colorectal, breast, liver and ovarian cancer (6-10). Numerous factors and processes are involved in the EMT of cancer cells, such as transforming growth factor (TGF)- $\beta$, hepatocyte growth factor (HGF), c-Met amplification, epidermal growth factor receptor (EGFR) mutation, and transcription factors ZEB1/2, Snail, Twist and Tiam1 (3). 
Among these, TGF- $\beta$ is considered one of the most important inducers of EMT. TGF- $\beta$ exerts an antitumor activity through the suppression of tumor growth at the early stage of tumor development, while at the late stage, it promotes tumor metastasis and EMT of tumor cells by reducing the adhesion molecule expression, accelerating tumor neovascularization and activating proteases that promote tumor metastasis (11).

MicroRNAs (miRNAs) are small non-coding RNA molecules (containing $\sim 22$ nucleotides) that are widely found in eukaryotes and viruses and regulate various cell functions. The mature miRNA binds to the non-coding region at the 3 -terminus of the target mRNA to regulate gene expression post-transcriptionally. miRNAs are also closely associated with tumor development and progression (12). The miR-200 family, an important class of EMT mediators, is found to mediate the proliferation, migration, invasion and metastasis of epithelial cell-derived malignant tumor cells in response to transforming growth factor $\beta 1$ (TGF- $\beta 1$ ) by regulating the expression of ZEB1/2 (13). In addition, to maintain the integrity of intestinal epithelium, TGF- $\beta 1$ induces EMT by suppressing Smad2 in a miR-200b-dependent manner (14).

Tumor metastasis is known to be organ specific. As tumor cells undergo EMT and become migratory, they may develop directional migration via chemokines. Chemokines are preferentially expressed in organs or tissues, and along with cell surface proteins, including integrins, they regulate the homing of multiple blood cell subsets to specific anatomic sites. During tumor development, the stromal cell-derived factor 1 (SDF-1)/CXC chemokine receptor type 4 (CXCR4) axis has been shown to be involved in the metastasis of various types of human cancer $(15,16)$.

The role of platelets in tumor progression has attracted increasing attention. Platelets, a major component of blood, contain $\alpha$ and dense granules and lysosomes, and play an important role in hemostasis, thrombosis and inflammation (17). In addition, platelets promote tumor metastasis. An increase in the platelet count is positively correlated with tumor metastasis, while a reduction in platelet count or inhibition of platelet function markedly inhibits tumor metastasis (18-21). The platelet $\alpha$ granules contain many substances, such as vascular endothelial growth factor (VEGF), SDF-1, plateletderived growth factor (PDGF) and TGF- $\beta$, which are involved in tumor progression when excreted $(22,23)$. Activation of the platelet $\alpha$ granule is mediated by the proteinase-activated receptor (PAR) signaling pathway $(23,24)$. PAR is a subfamily of the seven-pass transmembrane G-protein-coupled receptors, including PAR1, PAR2, PAR3 and PAR4 (25). PAR1 is expressed on platelets and is activated by thrombin or tissue factor in the tumor microenvironment $(26,27)$. Notably, PAR1 is also expressed in multiple tumor cells, and inhibition of PAR1 may suppress tumor growth and metastasis (28).

In clinical practice, thrombocythemia is predominantly found in patients with advanced tumors. It was generally thought that thrombocythemia develops only at the late stages of cancer, and platelets are only involved in the growth and metastasis of advanced tumors (29). However, it has been demonstrated that a large number of tumor cells migrate into the bloodstream even at an early stage, and these circulating tumor cells (CTCs) constitute nidi for tumor metastasis and recurrence (30). EMT and chemotaxis are essential for CTCs to enter the vasculature. In addition, platelet activation has been found to occur in the early stages of tumor development (30). Previous findings have shown that only direct contact between platelets and breast cancer cells induces EMT of breast cancer cells via the TGF- $\beta$ signaling pathway, suggesting that platelets induce EMT of tumor cells thus facilitating their entry into the bloodstream (31). Since tumor cells develop EMT prior to entering the bloodstream, we speculate that platelets may not need to directly contact tumor cells to induce their EMT, and may instead have a chemotactic effect on tumor cells. The aim of the present study was to investigate whether PAR1-activated platelets induce a colon cancer cell line to undergo EMT without direct contact with cancer cells, and to understand the role of platelets in the early-phase metastasis of colon cancer cells.

\section{Materials and methods}

Cell lines. The SW620 human colon cancer cell line was purchased from the Cell Bank of the Type Culture Collection of the Chinese Academy of Sciences (Shanghai, China). The cells were cultured in McCoy's $5 \mathrm{~A}$ medium containing $10 \%$ fetal bovine serum (FBS), $1 \%$ penicillin and $1 \%$ streptomycin at $37^{\circ} \mathrm{C}$ in $5 \% \mathrm{CO}_{2}$.

Antibodies and reagents. The PAR1 agonist TFLLR-NH ${ }_{2}$ was obtained from Sigma-Aldrich (St. Louis, MO, USA). The human CD62P-FITC antibody was purchased from AK-4 (eBioscience, Inc., San Diego, CA, USA). E-cadherin and vimentin rabbit anti-human antibodies were purchased from Abcam (Cambridge, MA, USA). PathScan ${ }^{\circledR}$ EMT Duplex IF kit was purchased from Cell Signaling Technology, Inc. (Shanghai, China). The ELISA kit for TGF- $\beta 1$ was obtained from Neobioscience Technology Co., Ltd. (Beijing, China). Transwell chambers (Corning Inc., Lowell, MA, USA) were used for the EMT assays. The cells were stained for flow cytometry using PE anti-human CD184/CXCR4 (12G5; BioLegend, San Diego, CA, USA).

Preparation of the platelets. Whole blood samples were collected from 10 healthy volunteers ( 8 men and 2 women, none of whom had any medical history or had received anticoagulants one week prior to blood sample collection). The blood samples were centrifuged at $200 \mathrm{xg}$ for $10 \mathrm{~min}$ to yield three cell layers: platelet rich plasma (PRP) on the upper layer, white cells at the middle layer, and red cells at the lower layer. Approximately $2 / 3$ of the PRP layer were transferred to a centrifugation tube containing $50 \mathrm{ng} / \mathrm{ml}$ prostaglandin E1 (PGE1), centrifuged at $22^{\circ} \mathrm{C}$ for $10 \mathrm{~min}$ and the supernatant was removed. The sediment platelets were washed twice with $5 \mathrm{ml}$ of phosphate-buffered saline (PBS) without calcium or magnesium. The platelets were re-suspended in solutions containing $5 \mathrm{mM}$ glucose and $0.25 \%$ bovine serum albumin (BSA), and adjusted to a concentration of $150,000 / \mu 1$ for the subsequent experiments.

Test for the optimal dose of platelet PARI agonist. To investigate platelet activation following treatment with various concentrations of TFLLR-NH ${ }_{2}$, CD62P (P-selectin) was used as a marker of platelet activation, and the rate of CD62P-positive platelets was detected using flow cytometry. TFLLR-NH ${ }_{2}$ was 
added to the platelet culture at final concentrations of $1,3,5$, 7 and $9 \mu \mathrm{M}$ in McCoy's 5A medium containing 10\% FBS, and incubated at $37^{\circ} \mathrm{C}$ for $15 \mathrm{~min}$, while non-treated platelets served as controls. The CD62P expression in the platelets was determined using flow cytometry (FC500 flow cytometer; Beckman Coulter, Inc., Chaska, MN, USA).

Detection of EMT. Based on the results of the above tests, $3 \mu \mathrm{M}$ TFLLR-NH ${ }_{2}$ was selected for subsequent experiments to determine whether activation of platelet PAR-1 induces EMT of the SW620 colon cancer cell line. Three groups were assigned: i) group 1, $100 \mu \mathrm{l}$ of activated platelet supernatant $+\mathrm{SW620}$ cells, ii) group 2, $100 \mu \mathrm{l}$ of supernatant of untreated platelets + SW620 cells and iii) group 3, $100 \mu 1$ of medium + SW620 cells. Three independent experiments were conducted.

After $24 \mathrm{~h}$ of culture at $37^{\circ} \mathrm{C}$, the SW620 cells were stained for E-cadherin and vimentin using the PathScan ${ }^{\circledR}$ EMT Duplex IF kit, and their expression was observed under a four-channel CLS-4HS laser confocal microscope (Thorlabs Inc., Newton, NJ, USA). Three independent experiments were conducted.

After incubation in 6-well plates for $24 \mathrm{~h}$, the E-cadherin and vimentin protein expression in the SW620 cells was detected using western blotting. Briefly, the cultured cells were washed once with PBS buffer and lysed in lysis buffer (1\% SDS, $50 \mathrm{mM}$ Tris, $\mathrm{pH}$ 7.4, $0.15 \mathrm{M} \mathrm{NaCl}, 1 \mathrm{mM} \mathrm{NaF}, 10 \mathrm{mM}$ phenylmethylsulfonyl fluoride, $1 \mathrm{mM}$ sodium orthovanadate, $1 \mathrm{mM}$ EDTA) for $5 \mathrm{~min}$ and passed through a 27-gauge needle. Lysates were centrifuged at $12,000 \mathrm{x} \mathrm{g}$ for $1 \mathrm{~min}$, the supernatants were collected, and protein concentrations were determined using a Bio-Rad DC protein assay (Bio-Rad, Hercules, CA, USA). Equal amounts of protein were separated by $10 \%$ SDS-PAGE and transferred to nitrocellulose membranes. The membranes were blocked with $3 \%$ BSA in TBST (10 mM Tris, pH 7.5, $150 \mathrm{mM} \mathrm{NaCl,} \mathrm{0.1 \%} \mathrm{Tween-20)}$ for $1 \mathrm{~h}$. Primary antibodies (1:200) and secondary antibodies were used according to the manufacturer's instructions. The blots were analyzed and quantified with the MCID imaging software (Imaging Research Inc., St. Catharines, ON, Canada). $\beta$-actin served as an internal reference.

Transwell migration assay. We assessed whether activation of platelet PAR-1 induces chemotaxis of the SW620 colon cancer cell line using a Transwell migration assay. Transwell chambers with an $8-\mu \mathrm{m}$ pore diameter and a $6.5 \mathrm{~mm}$ membrane diameter were used in a chemotaxis assay. Three groups were assigned: i) activated platelet supernatant group (cells were incubated in $600 \mu \mathrm{l}$ of the supernatant of the platelets activated by TFLLR-NH $\mathrm{N}_{2}$ at a final concentration of $1,3,5,7$ or $9 \mu \mathrm{M}$ in McCoy's 5A medium containing $10 \% \mathrm{FBS}$ ), ii) nonactivated platelet supernatant group (same as above but without TFLLR-NH $\mathrm{N}_{2}$ treatment), and iii) blank control group (cells were treated with McCoy's 5A medium containing 10\% FBS).

The upper Transwell chamber was filled with SW620 cells at a concentration of $2.5 \times 10^{5} / 100 \mu 1$, and the chemotaxis chamber was incubated at $37^{\circ} \mathrm{C}$ in $5 \% \mathrm{CO}_{2}$ for $18 \mathrm{~h}$. The nuclei of the cells migrating through the Transwell membrane were stained with $5 \mu \mathrm{g} / \mathrm{ml}$ of DAPI for $10 \mathrm{~min}$, and its fluorescence signal was observed under an inverted fluorescence microscope. The number of cells at five randomly selected fields was counted, and the mean count was calculated. Each experiment was repeated three times.

Quantification of TGF- $\beta 1$ levels in the platelet supernatant by ELISA. The supernatants of the platelets treated with TFLLR-NH ${ }_{2}$ at a final concentration of $1,3,5,7$ or $9 \mu \mathrm{M}$ in McCoy's 5A medium containing 10\% FBS and PBS were collected, and the TGF- $\beta 1$ released from platelets $\alpha$ granules was detected using an ELISA kit according to the manufacturer's instructions.

Quantitative PCR of miR-200b expression. Quantitative PCR (qPCR) was performed to detect the effect of the activated platelet supernatant on miR-200b expression in the SW620 cells. Platelets from healthy donors were incubated in $3 \mu \mathrm{M}$ TFLLR-NH $\mathrm{H}_{2}$ in McCoy's 5A medium containing $10 \%$ FBS for $15 \mathrm{~min}$, and the platelet supernatants were collected. The SW620 cells were treated with $0,60,120,240$ or $480 \mu 1$ of the supernatant for 24 or $48 \mathrm{~h}$. Total RNA was isolated from the cells using TRIzol ${ }^{\circledR}$ reagent, and its integrity was checked on agarose gel. After reverse transcription, qPCR was performed using a miR-200b primer (part No.: 4427975; assay ID: 002251) based on the specific cDNA template in $20 \mu \mathrm{l}$ of the reaction system containing $10 \mu \mathrm{l}$ of TaqMan ${ }^{\circledR}$ Universal PCR Master Mix, $1 \mu \mathrm{l}$ of diluted PreAmp product, $1 \mu \mathrm{l}$ of microRNA assay (all from ABI, Santa Monica, CA, USA) and $8 \mu 1$ of nucleasefree water under the following conditions: at $95^{\circ} \mathrm{C}$ for $10 \mathrm{~min}$, followed by 40 cycles at $95^{\circ} \mathrm{C}$ for $15 \mathrm{sec}$, and at $60^{\circ} \mathrm{C}$ for $60 \mathrm{sec}$. U6 snRNA (part No.: 4427975; assay ID: 001973; ABI) served as an internal reference. The relative miR-200b expression was estimated using the $2^{-\Delta \Delta \mathrm{Ct}}$ method.

Flow cytometric detection of CXCR4 expression on the SW620 cell surface. The TFLLR- $\mathrm{NH}_{2}$ and non-activated platelet groups were assigned. SW620 cells were seeded in 6-well plates at a concentration of $1.0 \times 10^{6}$ cells/well. The platelet supernatant $(100 \mu \mathrm{l})$ activated at a final concentration of $3 \mu \mathrm{M}$ TFLLR- $\mathrm{NH}_{2}$ in McCoy's 5A medium containing $10 \%$ FBS was added to the TFLLR-NH $\mathrm{N}_{2}$ group, while the same volume of medium was transferred to the blank control. After a $24 \mathrm{~h}$ culture, the cells were collected, digested with pancreatic enzymes and the cell density was adjusted to $1.5 \times 10^{7}$ cells $/ \mathrm{ml}$. The CXCR4 level on the SW620 cell surface was determined using flow cytometry. Experiments were repeated three times.

Statistical analysis. Data are presented as mean \pm standard deviation (SD). Statistical analyses were performed using the statistical software SPSS version 13.0 (SPSS, Inc., Chicago, IL, USA). The statistical significance of the differences between the means was determined by the Student's t-test when analyzing two independent samples, while analysis of variance (ANOVA) was employed for multiple independent samples. Rank sum test was used to make comparisons among multiple groups when the variances of the groups were heterogeneous. $\mathrm{P}<0.05$ was considered to indicate a statistically significant result.

\section{Results}

Activation of platelets by the PAR agonist TFLLR-NH $\mathrm{H}_{2}$. To detect platelet activation following treatment with various 


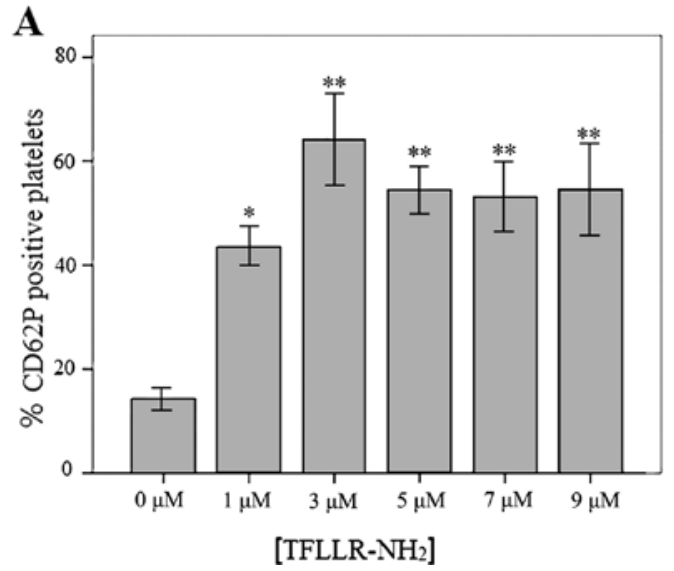

B
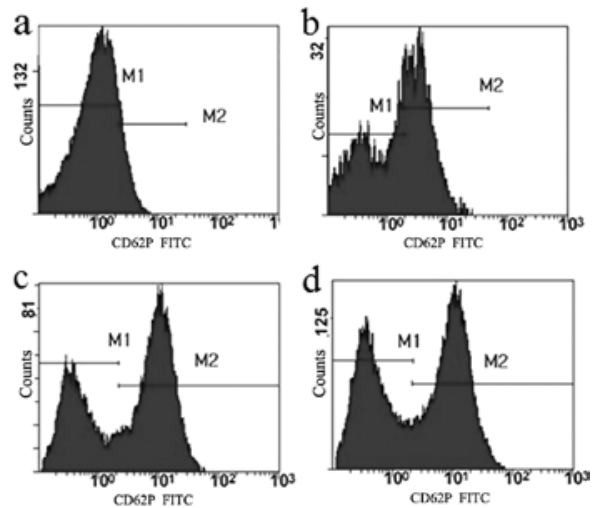

Figure 1. Flow cytometry detection of CD62P in the platelets treated with the PAR1 agonist TFLLR-NH $2 .(A) C_{2} 62 \mathrm{P}$ expression in the platelets treated with different concentrations of TFLLR- $\mathrm{NH}_{2}$ as detected by flow cytometry (mean \pm standard deviation of three independent experiments). ${ }^{*} \mathrm{P}<0.05$ and ${ }^{* * *} \mathrm{P}<0.01$. (B) Representative FACS plots for CD62P expression in the platelets activated by (a) 0, (b) 1, (c) 3 and (d) $10 \mu \mathrm{M}$ TFLLR-NH 2 . M1, CD62P-negative region; M2, CD62P-positive region. PAR1, protease-activated receptor-1.
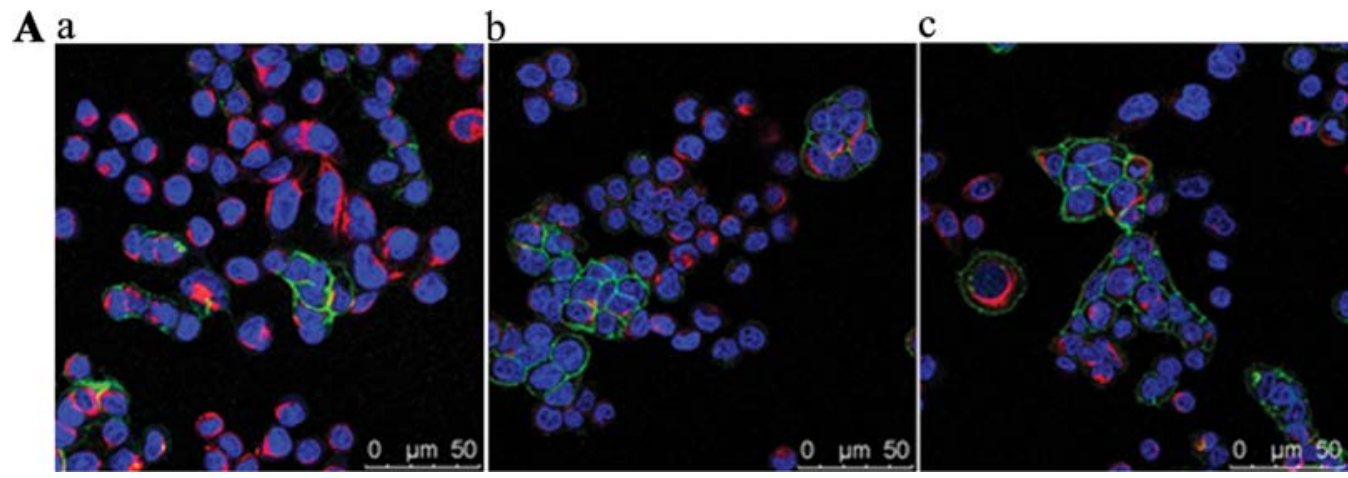

B

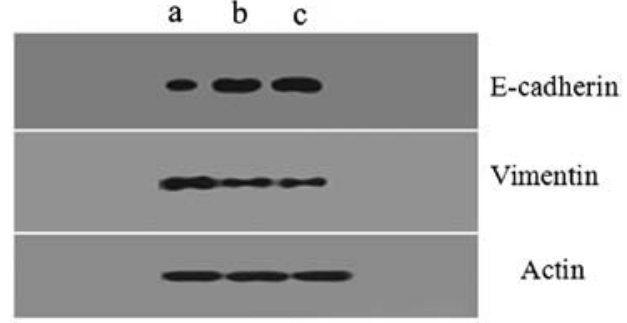

Figure 2. (A) Confocal immunofluorescence images showing the expression of vimentin (red) and E-cadherin (green) in the SW620 cells after $24 \mathrm{~h}$ treatment with (a) PAR1-activated platelet supernatant, (b) non-activated platelet supernatant and (c) no treatment. SP magnification, x400. (B) Expression of E-cadherin or vimentin protein in the SW620 cells detected by western blotting. (a) PAR1-activated platelets supernatant, (b) non-activated platelets supernatant and (c) medium control. PAR1, protease-activated receptor-1. concentrations of TFLLR-NH ${ }_{2}$, the rate of CD62P (P-selectin)positive platelets was determined using flow cytometry. The rates of CD62P-positive platelets were $(43.52 \pm 1.5) \%,(64.22 \pm 3.60) \%$, $(54.46 \pm 1.82) \%,(53.15 \pm 2.7) \%$ and $(54.63 \pm 3.66) \%$ in the platelets treated with TFLLR-NH $\mathrm{N}_{2}$ at a final concentration of $1,3,5,7$ and $9 \mu \mathrm{M}$, respectively, all of which were significantly greater $(\mathrm{P}<0.05)$ than the rates in the blank control (no TFLLR-NH ${ }_{2}$ ) group (14.35 \pm 0.86$) \%$ (Fig. 1A and B). Thus, $3 \mu \mathrm{M}$ was selected as the dose of TFLLR-NH $\mathrm{N}_{2}$ for platelet activation.

EMT of SW620 cells. To detect whether platelet activation induced EMT of the SW620 cells, immunofluorescence and western blotting were employed to determine the expression of EMT markers E-cadherin and vimentin. Laser confocal microscopy showed that the supernatant of TFLLR-NH $\mathrm{N}_{2}$-activated platelets triggered the downregulation of E-cadherin expression and the upregulation of vimentin expression (Fig. 2A) in the SW620 cells compared to the cells treated with medium or with the supernatant of untreated platelets. Western blot analysis showed a similar finding (Fig. 2B). The grey value of E-cadherin was 0.225 for cells treated with activated platelet supernatant, which was lower than that for the cells treated with medium or with the supernatant of untreated platelets $(0.758$ and 0.769 , respectively). However, the grey value of vimentin was 0.616 for cells treated with activated platelet supernatant, which was greater than that for the cells treated with medium or with the supernatant of untreated platelets $(0.211$ and 0.234 , respectively). These findings suggested that platelet activation may induce the EMT of the SW620 cells.

The supernatant of TFLLR-NH $\mathrm{H}_{2}$-activated platelets induces SW620 cell migration. A chemotaxis assay was performed to investigate the chemotactic effect of platelet activation on tumor cells. Our findings showed no significant difference in the number of SW620 cells that migrated through the Transwell membrane/field between the group with the 
A

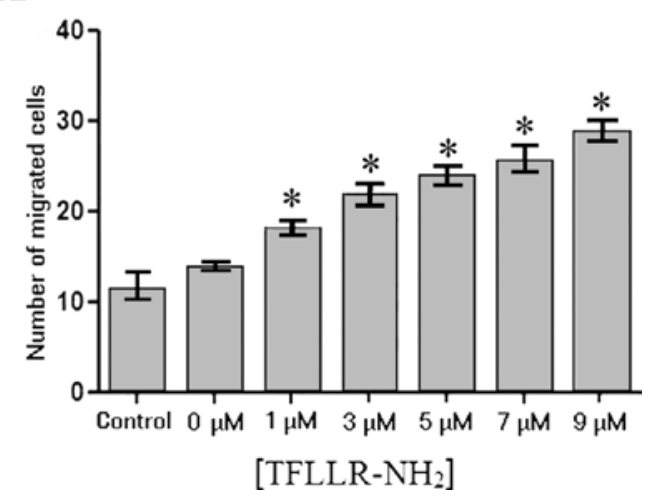

B $\mathrm{a}$

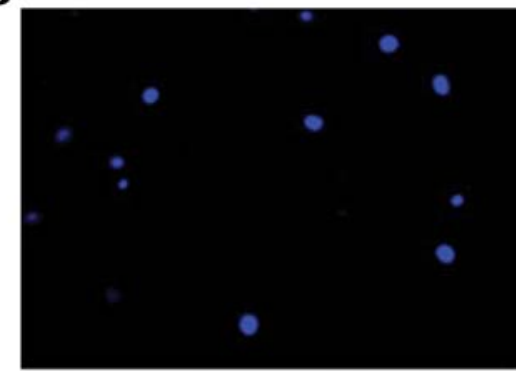

c

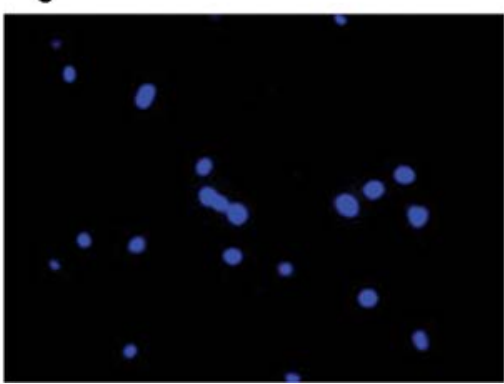

b

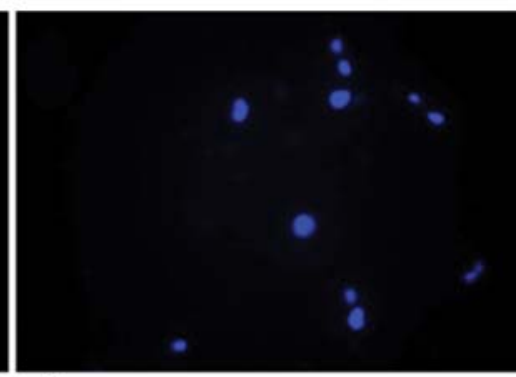

d

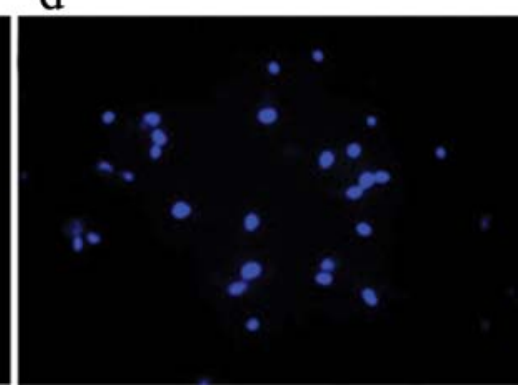

Figure 3. (A) Migration of the SW620 cells induced by platelet activation examined by Transwell migration assay. The number of the migrated SW620 cells induced by platelet supernatants extracted from the platelets activated by different concentrations of TFLLR-NH . $^{*} \mathrm{P}<0.05$ compared to the control. (B) Fluorescence microscopy image of the upper Transwell chamber after migration of the SW620 cells towards the activated platelet supernatant. The nuclei were stained with DAPI. (a) Media only control, (b) no TFLLR-NH $\mathrm{N}_{2}$ in the platelet culture, (c) $1 \mu \mathrm{M}_{\mathrm{TFLLR}} \mathrm{NH}_{2}$ and (d) $7 \mu \mathrm{M}$ TFLLR-NH .

supernatant of untreated platelets and the blank control group $(11.33 \pm 2.08$ vs. $13.67 \pm 0.58, \mathrm{P}>0.05)$. When using conditioned media from the platelets treated with TFLLR-NH $\mathrm{NH}_{2}$ at a final concentration of $1,3,5,7$ and $9 \mu \mathrm{M}$, the number of SW620 cells migrating through the membrane to the platelet supernatant was $18 \pm 1,21.67 \pm 1.53,23.67 \pm 1.53,25.33 \pm 2.08$ and $28.67 \pm 1.53$, respectively (Fig. $3 \mathrm{~A}$ ), all of which were significantly greater $(\mathrm{P}<0.05)$ than the numbers in the blank control (no TFLLR-NH ${ }_{2}$ ) group and in the group with the supernatant of the untreated platelets $(\mathrm{P}<0.05)$. A dose-dependent increase in the number of the cells migrating through the Transwell membrane was observed (Fig. 3B). These findings indicated that the supernatant of the TFLLR- $\mathrm{NH}_{2}$-activated platelets had a chemotactic effect on the SW620 cells.

TGF- $\beta 1$ levels in the TFLLR-NH $\mathrm{H}_{2}$-activated platelet supernatant. The TGF- $\beta 1$ levels were $41.42 \pm 3.60,119.27 \pm 5.16$, $197.11 \pm 9.21,231.37 \pm 7.26$ and $241.33 \pm 17.60 \mathrm{pg} / \mathrm{ml}$ in the supernatants of the platelets activated by TFLLR-NH $\mathrm{N}_{2}$ at a final concentration of $1,3,5,7$ and $9 \mu \mathrm{M}$, respectively, reflecting a dose-dependent increase in the TGF- $\beta 1$ secretion, and the TGF- $\beta 1$ level was significantly higher in the activated platelet supernatant than in that of the control group

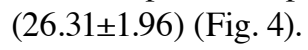

miR-200b expression in SW620 cells. Although miR-200b has been shown to be involved in the regulation of EMT (14), the effect of the platelet activation on miR-200b expression remains unclear. qPCR was performed to investigate the effect of $3 \mu \mathrm{M}$ TFLLR-NH $\mathrm{H}_{2}$-treated platelet supernatant on the miR200 b expression in the SW620 cells. Our findings showed that following treatment with activated platelet supernatant for $48 \mathrm{~h}$, no significant difference was found in the relative

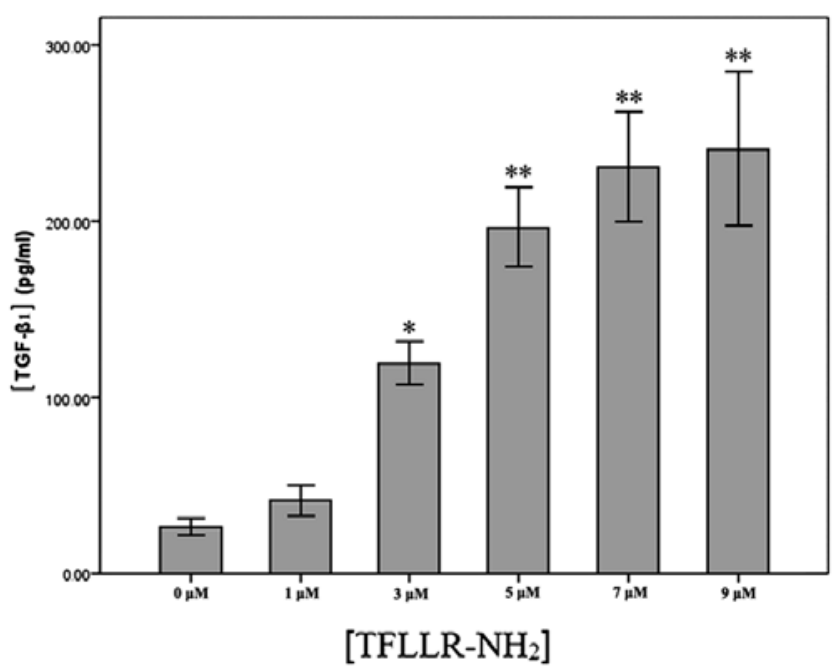

Figure 4 . The levels of TGF- $\beta 1$ released by platelets treated with different concentrations of TFLLR- $\mathrm{NH}_{2}$ as detected by ELISA. The TGF- $\beta 1$ secretion was significantly higher in the activated platelet group than that in the control, and the TGF- $\beta 1$ level increased in a dose-dependent manner in the activated platelet groups. ${ }^{*} \mathrm{P}<0.05$ and ${ }^{* *} \mathrm{P}<0.01$ vs. the control group. TGF- $\beta 1$, transforming growth factor $\beta 1$.

miR-200b expression between the non-treated platelet supernatant control and the TFLLR-NH $\mathrm{N}_{2}$ treatment group $(\mathrm{P}>0.05)$ (Fig. 5B). The relative miR-200b expression was $0.118 \pm 0.013$, $0.105 \pm 0.006,0.090 \pm 0.001$ and $0.073 \pm 0.003$ in SW620 cells treated with $60,120,240$ and $480 \mu \mathrm{l}$ of the platelet supernatant for $24 \mathrm{~h}$, respectively, compared to $0.117 \pm 0.007$ in the blank control group. However, the relative miR-200b expression was lower in the SW620 cells treated with 240 and $480 \mu \mathrm{l}$ of the platelet supernatant than in the control group (Fig. 5A, 
A

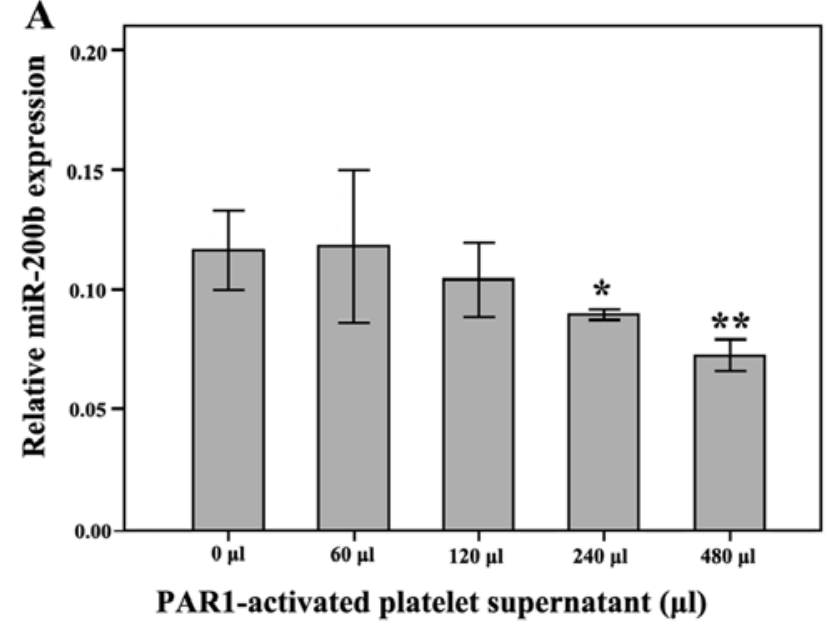

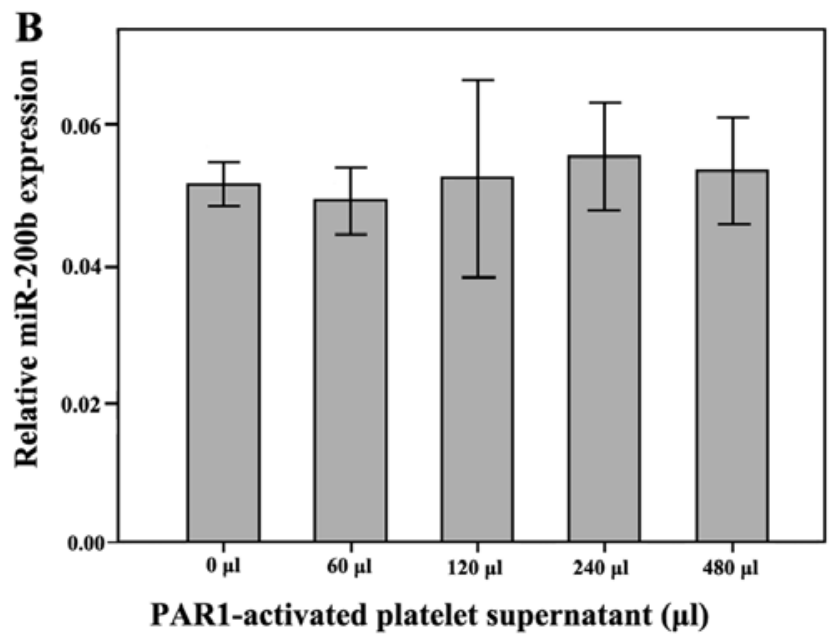

Figure 5. Expression of miR-200b of the SW620 treated with different volumes of the PAR1-activated platelet supernatant detected by qPCR at (A) 24 or (B) $48 \mathrm{~h}$. (A) After $24 \mathrm{~h}$ the groups treated with 60 and $120 \mu \mathrm{l}$ of platelet supernatant did not indicate significant difference (P>0.05) compared to the control group, whereas those treated with 240 and $480 \mu 1$ showed a significantly lower miR-200b expression. ${ }^{*} \mathrm{P}<0.05$ and ${ }^{* *} \mathrm{P}<0.01$. PAR1, protease-activated receptor-1.

$\mathrm{P}<0.05$ ), suggesting that the miR-200b expression appeared to decline with increasing volumes of the platelet supernatant, while in the SW620 cells treated with 60 and $120 \mu 1$ of the platelet supernatant there were no significant differences with the non-treated platelet supernatant control group $(\mathrm{P}>0.05)$.

Effect of TFLLR-NH $\mathrm{H}_{2}$-activated platelet supernatant on CXCR4 expression in the SW620 cells. Cell surface CXCR4, when bound to its ligand SDF-1, induces the directional migration of tumor cells (32). The aforementioned results showed that TFLLR-NH $\mathrm{N}_{2}$-activated platelets, not only induced the chemotaxis of the SW620 cells, but also stimulated TGF- $\beta 1$ secretion by platelets. Flow cytometry was used to investigate the effect of platelet activation on CXCR4 expression on SW620 cells. Our findings showed that $(40.89 \pm 6.74) \%$ of the SW620 cells were positive for CXCR4 $24 \mathrm{~h}$ after treatment with the supernatant of the platelets activated by $3 \mu \mathrm{M}$ TFLLR-NH${ }_{2}$, which was significantly greater than that $(3.47 \pm 1.40) \%$ in the non-activated platelet group $(\mathrm{P}<0.01$; Fig. 6$)$.

\section{Discussion}

In the present study, we found that PAR1 agonist TFLLR-NH activated platelets released TGF- $\beta 1$ leading to the upregulation of CXCR4 and the inhibition of miR-200b expression in SW620 cells, ultimately inducing EMT-phenotype and migration in vitro. Our findings suggest that the activation of platelet PAR1 may be important in the initial stages of tumor metastasis, and early antiplatelet therapy may be of great significance to suppress colorectal cancer metastasis and improve the survival rate.

Platelet-tumor cell interaction is extremely complex in tumor microenvironments. It has been reported that tumor cells upregulate the expression of tissue factor (TF) leading to an increase in thrombin, which activates platelet PAR1 or PAR4 $(33,34)$. In addition, tumor cells can directly secrete thrombin into microenvironments to activate platelets (35). Inflammation and angiogenesis are usually present inside tumors, and the distribution of new blood vessels is

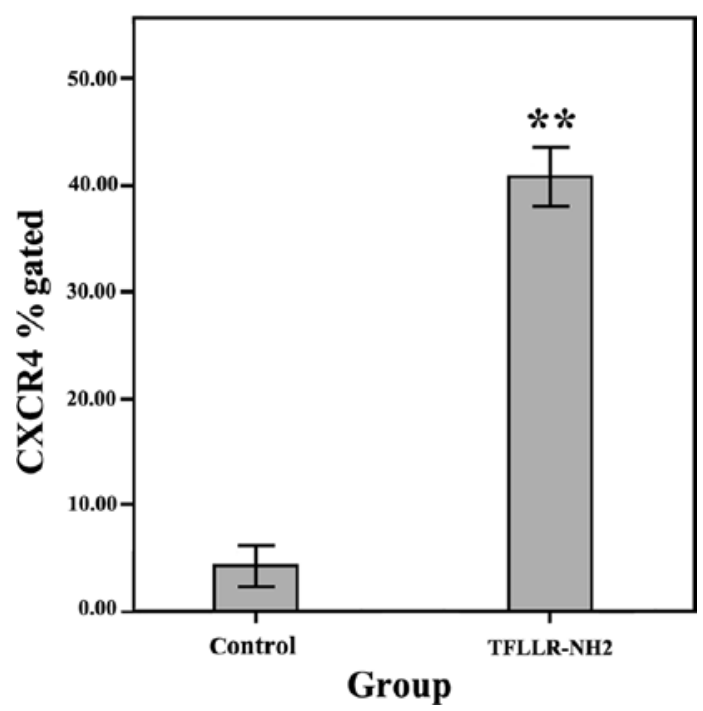

Figure 6. CXCR4 expression of SW620 cells treated with culture medium (control) or with supernatants of the platelets cultured in $3 \mu \mathrm{M}$ TFLLR-NH as detected by flow cytometry. ${ }^{* *} \mathrm{P}<0.01$. CXCR4, CXC chemokine receptor type 4.

disorganized. These pathological changes may cause the slowdown of blood circulation in and surrounding the tumors, thereby increasing the probability of tumor-activating platelet deposition (36), which may promote tumor cell growth and metastasis.

Labelle et al (37) found that the platelet-breast cancer cell interaction promoted tumor cell EMT and metastasis. Since the supernatant of the thrombin-activated platelets did not induce tumor cell EMT within $48 \mathrm{~h}$, the direct contact between platelets and tumor cells was considered essential for the development of EMT (38). However, this does not concur with our findings. In the present study, the supernatant of platelets activated by a PAR 1 agonist TFLLR-NH $\mathrm{NH}_{2}$, was found to induce EMT of the SW620 cells within $24 \mathrm{~h}$, indicating that tumor cell EMT may occur without the direct contact between platelets and tumor cells. In addition, Labelle et al (37) reported that 
the induction of breast cancer EMT by platelets required at least one week. However, the sensitivity to cytokines may vary in tumor cells, resulting in varying potentials and speeds of EMT. For example, it has been shown that EMT occurs in the tumor cells NMuMG, A549 and MDA-MB-231 $24 \mathrm{~h}$ after the addition of TGF- $\beta$ (38).

Our findings show that the activated platelets secreted TGF- $\beta 1$, and conditioned media from the activated platelet culture led to the downregulation of miR-200b expression in the SW620 cells. Accumulating evidence has demonstrated that multiple factors released by platelets induce tumor cell EMT, of which TGF- $\beta$ is the most extensively investigated $(37,38)$. TGF- $\beta$ has been found to promote the metastasis of multiple tumors through the induction of cancer cell EMT $(12,14,39)$. Besides activating the Smad pathway, TGF- $\beta$ induces tumor cell EMT through other means, including the Ras-Erk/MAPK, p38/MAPK, JNK, Rho GTPase and PI3K/Akt pathways (12). In addition, TGF- $\beta$ has been reported to mediate EMT via the regulation of miRNA transcription (14). It has been shown that TGF- $\beta 1$ signaling downregulates the expression of the miR-200 family by activating Akt2, leading to the upregulation of ZEB1 and ZEB2 (39). Moreover, ZEB2 binds to the miR-200 promoter to inhibit its transcription, resulting in the formation of a negative feedback loop, which further stimulates the EMT of tumor cells (40).

In addition, results of the present study have shown that PAR1 agonist-activated platelets had a chemotactic effect on the SW620 colon cancer cell line. It is well known that activated platelets may be involved in the chemotaxis of various cells, and thus participate in various pathological processes, such as inflammation, thrombogenesis and arteriosclerosis (41). During inflammation, platelets promote their adhesion to other cells in the blood by expressing receptors such as $\beta 3$ integrins, and are involved in the chemotaxis of inflammatory cells by releasing a large number of chemokines (42). Our findings confirm the chemotactic effect of platelets on malignant tumor cells. If a solid tumor exceeds $2 \mathrm{~mm}$ in diameter, new blood vessels form, a process accompanied by the infiltration of inflammatory cells. When platelets pass through tumors via the bloodstream, they may be activated by specific cytokines released by tumor cells or by mesenchymal cells in tumor microenvironments, and activated platelets may in turn induce tumor cell EMT and migration into blood vessels. Therefore, some clinically diagnosed early-stage tumors are virtually at an 'advanced phase'. This may explain the reason for some cancer patients developing early-stage metastasis. It has been shown that an antiplatelet agent such as aspirin may reduce the metastatic rate of malignant tumors and improve prognosis (43).

In addition, our findings show that the activated platelet culture supernatant upregulated the expression of CXCR4 on the surface of SW620 cells, suggesting platelets actively induce the migration of tumor cells into blood vessels. The chemokine receptor CXCR4 is widely present in multiple tumors, and a high CXCR4 expression is a predictive marker of tumor metastasis and results in a worse prognosis (44-46). For example, a low CXCR4 expression is detected in normal breast tissues, while a high expression is found in breast cancer tissues (47). The CXCR4-SDF-1 interaction may lead to actin polymerization and pseudopod formation, thereby resulting in chemotaxis and invasion (47), while the specific blockade of
CXCR4 inhibits the metastasis of breast cancer cells to lymph nodes and bone marrow (47). In addition, a high CXCR4 expression was found to correlate with bone metastasis in prostate cancer, while a neutralizing antibody against CXCR4 may block the bone metastasis of prostate cancer (48).

The interaction between tumor and microenvironment is complex, and the interaction between tumor and the cell components in the microenvironment is potent. The present study only investigated the effect of static platelets on tumor cells. Future studies are required to evaluate the impact of platelets on tumor cells in dynamic bloodstream. In addition to TGF- $\beta 1$, platelet-derived PDGF plays an important role in inducing cell EMT (49). Notably, platelets have recently been found to enter tumor tissues in animal models (50). Further studies are warranted to evaluate the role of platelets in tumor progression and the difference between intratumoral and intravascular platelet-mediated tumor activation.

In conclusion, PAR1-activated platelets may induce EMT of the SW620 colon cancer cell line via the TGF- $\beta$ pathway, and they provide chemotactic signals to the SW620 cells which lead to the upregulation of CXCR4 on the cancer cell surface. The present study provides evidence showing a molecular mechanism potentially underlying colorectal cancer metastasis and contributes to supporting the potential value of early antiplatelet therapy for colorectal cancer.

\section{Acknowledgements}

This study was supported by a Hebei Province Department of Education Major Project Grant (grant no. ZD20131052).

\section{References}

1. Kalluri $\mathrm{R}$ and Weinberg RA: The basics of epithelialmesenchymal transition. J Clin Invest 119: 1420-1428, 2009.

2. Kang $\mathrm{Y}$ and Massagué J: Epithelial-mesenchymal transitions: Twist in development and metastasis. Cell 118: 277-279, 2004.

3. Findlay VJ, Wang C, Watson DK and Camp ER: Epithelial-tomesenchymal transition and the cancer stem cell phenotype: Insights from cancer biology with therapeutic implications for colorectal cancer. Cancer Gene Ther 21: 181-187, 2014.

4. Wendt MK, Allington TM and Schiemann WP: Mechanisms of the epithelial-mesenchymal transition by TGF-beta. Future Oncol 5: 1145-1168, 2009.

5. Thiery JP: Epithelial-mesenchymal transitions in cancer onset and progression. Bull Acad Natl Med 193: 1969-1979, 2009 (In French).

6. Murai T, Yamada S, Fuchs BC, Fujii T, Nakayama G, Sugimoto H, Koike M, Fujiwara M, Tanabe KK and Kodera Y: Epithelial-tomesenchymal transition predicts prognosis in clinical gastric cancer. J Surg Oncol 109: 684-689, 2014.

7. Zhang W, Wu Y, Yan Q, Ma F, Shi X, Zhao Y, Peng Y, Wang J and Jiang B: Deferoxamine enhances cell migration and invasion through promotion of HIF-1 $\alpha$ expression and epithelialmesenchymal transition in colorectal cancer. Oncol Rep 31: 111-116, 2014.

8. Leibovich-Rivkin T, Liubomirski Y, Bernstein B, Meshel T and Ben-Baruch A: Inflammatory factors of the tumor microenvironment induce plasticity in nontransformed breast epithelial cells: EMT, invasion, and collapse of normally organized breast textures. Neoplasia 15: 1330-1346, 2013.

9. Yau WL, Lam CS, Ng L, Chow AK, Chan ST, Chan JY, Wo JY, Ng KT, Man K, Poon RT, et al: Over-expression of miR-106b promotes cell migration and metastasis in hepatocellular carcinoma by activating epithelial-mesenchymal transition process. PLoS One 8: e57882, 2013.

10. Lili LN, Matyunina LV, Walker LD, Wells SL, Benigno BB and McDonald JF: Molecular profiling supports the role of epithelialto-mesenchymal transition (EMT) in ovarian cancer metastasis. J Ovarian Res 6: 49, 2013. 
11. Pardali K and Moustakas A: Actions of TGF-beta as tumor suppressor and pro-metastatic factor in human cancer. Biochim Biophys Acta 1775: 21-62, 2007.

12. Nelson KM and Weiss GJ: MicroRNAs and cancer: Past, present, and potential future. Mol Cancer Ther 7: 3655-3660, 2008

13. Gregory PA, Bert AG, Paterson EL, Barry SC, Tsykin A, Farshid G, Vadas MA, Khew-Goodall Y and Goodall GJ: The miR-200 family and miR-205 regulate epithelial to mesenchymal transition by targeting ZEB1 and SIP1. Nat Cell Biol 10: 593-601, 2008.

14. Chen Y, Xiao Y, Ge W, Zhou K, Wen J, Yan W, Wang Y, Wang B, Qu C, Wu J, et al: miR-200b inhibits TGF- $\beta 1$-induced epithelialmesenchymal transition and promotes growth of intestinal epithelial cells. Cell Death Dis 4: e541, 2013.

15. Jankowski K, Kucia M, Wysoczynski M, Reca R, Zhao D, Trzyna E, Trent J, Peiper S, Zembala M, Ratajczak J, et al: Both hepatocyte growth factor (HGF) and stromal-derived factor-1 regulate the metastatic behavior of human rhabdomyosarcoma cells, but only HGF enhances their resistance to radiochemotherapy. Cancer Res 63: 7926-7935, 2003

16. Yang P, Liang SX, Huang WH, Zhang HW, Li XL, Xie LH, $\mathrm{Du} \mathrm{CW}$ and Zhang GJ: Aberrant expression of CXCR4 significantly contributes to metastasis and predicts poor clinical outcome in breast cancer. Curr Mol Med 14: 174-184, 2014.

17. Bazzoni G, Dejana E and Del Maschio A: Platelet-neutrophi interactions. Possible relevance in the pathogenesis of thrombosis and inflammation. Haematologica 76: 491-499, 1991.

18. Hwang SG, Kim KM, Cheong JH, Kim HI, An JY, Hyung WJ and Noh SH: Impact of pretreatment thrombocytosis on bloodborne metastasis and prognosis of gastric cancer. Eur J Surg Oncol 38: 562-567, 2012

19. Gao J, Zhang HY and Xia YF: Increased platelet count is an indicator of metastasis in patients with nasopharyngeal carcinoma. Tumour Biol 34: 39-45, 2013

20. Sasaki K, Kawai K, Tsuno NH, Sunami E and Kitayama J: Impact of preoperative thrombocytosis on the survival of patients with primary colorectal cancer. World J Surg 36: 192-200, 2012.

21. Kaneko MK, Kunita A, Abe S, Tsujimoto Y, Fukayama M, Goto K, Sawa Y, Nishioka Y and Kato Y: Chimeric antipodoplanin antibody suppresses tumor metastasis through neutralization and antibody-dependent cellular cytotoxicity. Cancer Sci 103: 1913-1919, 2012.

22. Blair P and Flaumenhaft R: Platelet alpha-granules: Basic biology and clinical correlates. Blood Rev 23: 177-189, 2009.

23. Chatterjee M, Huang Z, Zhang W, Jiang L, Hultenby K, Zhu L, $\mathrm{Hu} \mathrm{H}$, Nilsson GP and Li N: Distinct platelet packaging, release, and surface expression of proangiogenic and antiangiogenic factors on different platelet stimuli. Blood 117: 3907-3911, 2011.

24. Tamura S, Suzuki H, Hirowatari Y, Hatase M, Nagasawa A, Matsuno K, Kobayashi S and Moriyama T: Release reaction of brain-derived neurotrophic factor (BDNF) through PAR1 activation and its two distinct pools in human platelets. Thromb Res 128: e55-e61, 2011.

25. Cottrell GS, Coelho AM and Bunnett NW: Protease-activated receptors: The role of cell-surface proteolysis in signalling. Essays Biochem 38: 169-183, 2002.

26. Schaffner F and Ruf W: Tissue factor and PAR2 signaling in the tumor microenvironment. Arterioscler Thromb Vasc Biol 29: 1999-2004, 2009.

27. Jiang L, Xu C, Yu S, Liu P, Luo D, Zhou Q, Gao C and Hu H: A critical role of thrombin/PAR-1 in ADP-induced platelet secretion and the second wave of aggregation. J Thromb Haemost 11: 930-940, 2013.

28. Fujimoto D, Hirono Y, Goi T, Katayama K, Matsukawa S and Yamaguchi A: The activation of proteinase-activated receptor-1 (PAR1) mediates gastric cancer cell proliferation and invasion. BMC Cancer 10: 443, 2010.

29. O'Keefe SC, Marshall FF, Issa MM, Harmon MP and Petros JA Thrombocytosis is associated with a significant increase in the cancer specific death rate after radical nephrectomy. J Urol 168: 1378-1380, 2002

30. Lim SH, Becker TM, Chua W, Caixeiro NJ, Ng WL, Kienzle N, Tognela A, Lumba S, Rasko JE, de Souza P, et al: Circulating tumour cells and circulating free nucleic acid as prognostic and predictive biomarkers in colorectal cancer. Cancer Lett 346 24-33, 2014.
31. Almog $\mathrm{N}$ and Klement GL: Platelet proteome and tumor dormancy: Can platelets content serve as predictive biomarkers for exit of tumors from dormancy? Cancers 2: 842-858, 2010

32. Wang K, Zhao X, Kuang C, Qian D, Wang H, Jiang H, Deng M and Huang L: Overexpression of SDF-1 $\alpha$ enhanced migration and engraftment of cardiac stem cells and reduced infarcted size via CXCR4/PI3K pathway. PLoS One 7: e43922, 2012.

33. Zhou H, Hu H, Shi W, Ling S, Wang T and Wang $\mathrm{H}$ : The expression and the functional roles of tissue factor and proteaseactivated receptor-2 on SW620 cells. Oncol Rep 20: 1069-1076, 2008.

34. Bambace NM and Holmes CE: The platelet contribution to cancer progression. J Thromb Haemost 9: 237-249, 2011.

35. Hu L, Lee M, Campbell W, Perez-Soler R and Karpatkin S: Role of endogenous thrombin in tumor implantation, seeding, and spontaneous metastasis. Blood 104: 2746-2751, 2004.

36. Nishimura S, Manabe I, Nagasaki M, Seo K, Yamashita H, Hosoya Y, Ohsugi M, Tobe K, Kadowaki T, Nagai R, et al: In vivo imaging in mice reveals local cell dynamics and inflammation in obese adipose tissue. J Clin Invest 118: 710-721, 2008.

37. Labelle M, Begum S and Hynes RO: Direct signaling between platelets and cancer cells induces an epithelial-mesenchymallike transition and promotes metastasis. Cancer Cell 20: 576-590, 2011.

38. Bae E, Kim SJ, Hong S, Liu F and Ooshima A: Smad3 linker phosphorylation attenuates Smad3 transcriptional activity and TGF- $\beta 1 /$ Smad3-induced epithelial-mesenchymal transition in renal epithelial cells. Biochem Biophys Res Commun 427: 593-599, 2012

39. Xiong M, Jiang L, Zhou Y, Qiu W, Fang L, Tan R, Wen P and Yang J: The miR-200 family regulates TGF- $\beta 1$-induced renal tubular epithelial to mesenchymal transition through Smad pathway by targeting ZEB1 and ZEB2 expression. Am J Physiol Renal Physiol 302: F369-F379, 2012

40. Brabletz S and Brabletz T: The ZEB/miR-200 feedback loop - a motor of cellular plasticity in development and cancer? EMBO Rep 11: 670-677, 2010.

41. Gawaz M, Langer H and May AE: Platelets in inflammation and atherogenesis. J Clin Invest 115: 3378-3384, 2005.

42. Blair P and Flaumenhaft R: Platelet $\alpha$-granules: Basic biology and clinical correlates. Blood Rev 23: 177-189, 2009.

43. Rothwell PM, Wilson M, Elwin CE, Norrving B, Algra A, Warlow CP and Meade TW: Long-term effect of aspirin on colorectal cancer incidence and mortality: 20-year follow-up of five randomised trials. Lancet 376: 1741-1750, 2010.

44. Lin MS, Huang JX, Zhu J and Shen HZ: Elevation of platelet count in patients with colorectal cancer predicts tendency to metastases and poor prognosis. Hepatogastroenterology 59: 1687-1690, 2012

45. Zhang SS, Han ZP, Jing YY, Tao SF, Li TJ, Wang H, Wang Y, Li R, Yang Y, Zhao X, et al: $\mathrm{CD} 133^{+} \mathrm{CXCR} 4^{+}$colon cancer cells exhibit metastatic potential and predict poor prognosis of patients. BMC Med 10: 85, 2012.

46. Balabanian K, Lagane B, Infantino S, Chow KY, Harriague J, Moepps B, Arenzana-Seisdedos F, Thelen M and Bachelerie F: The chemokine SDF-1/CXCL12 binds to and signals through the orphan receptor RDC1 in T lymphocytes. J Biol Chem 280: 35760-35766, 2005.

47. Müller A, Homey B, Soto H, Ge N, Catron D, Buchanan ME, McClanahan T, Murphy E, Yuan W, Wagner SN, et al: Involvement of chemokine receptors in breast cancer metastasis. Nature 410: 50-56, 2001

48. Sun YX, Schneider A, Jung Y, Wang J, Dai J, Wang J, Cook K, Osman NI, Koh-Paige AJ, Shim H, et al: Skeletal localization and neutralization of the SDF-1(CXCL12)/CXCR4 axis blocks prostate cancer metastasis and growth in osseous sites in vivo. J Bone Miner Res 20: 318-329, 2005.

49. Wu Q, Hou X, Xia J, Qian X, Miele L, Sarkar FH and Wang Z: Emerging roles of PDGF-D in EMT progression during tumorigenesis. Cancer Treat Rev 39: 640-646, 2013

50. Devarajan E, Song YH, Krishnappa S and Alt E: Epithelialmesenchymal transition in breast cancer lines is mediated through PDGF-D released by tissue-resident stem cells. Int J Cancer 131: 1023-1031, 2012. 